\title{
Involving Roma parents: analysing the good practice of a primary school in Ghent
}

\author{
Recently, societal and academic attention toward the topic of Roma \\ integration has been increasing. With this paper, we aim to make a \\ contribution in the domain of educational research. We explore strategies \\ schools can adopt to improve the involvement of Roma parents. Using a \\ theory-based stakeholder evaluation, we more specifically analyse how the \\ organisational model of a primary school contributes to the establishment \\ of trust between both parties. The results show that the theoretical \\ principles guiding the daily school practices and interventions are aligned \\ with the needs and specificity of the target audience, but are also broadly \\ supported by the school staff. As such, the organizational structure of the \\ school contributes to the support of the school staff for the global school \\ vision and to the overall success of the approach. Nevertheless, some \\ tension remains between team members working on the 'care' aspect and \\ teachers working solely within the classrooms.
}

Keywords: Roma, education, good practice, trust, parental involvement

Word count: 7649 words (manuscript $)+326$ words $($ tables $)=7975$ words

\section{Introduction}

The recent enlargement of the European Union (EU) and the right to the freedom of movement allowed citizens from Eastern European countries to migrate to Western Europe more easily. Among these newcomers are many Roma, who often fled from incidents of socio-economic discrimination and widespread racism (FRA 2012; CFHR 2012).

Roma are the largest ethnic minority group within Europe, with an estimated number of 11 million (ABB 2012). Both in their home countries and receiving countries, they are described in rather problematic terms that generally refer to difficulties involving employment, housing, health and education (FRA 2012). On the EU level, the European Commission identified the same four core areas in the EU framework for National Roma Integration Strategies up to 2020 (COM(2011) 173 
final). In Flanders, Belgium, the Roma population is estimated to be around 15,000 (ABB 2012). The Roma-presence in Flanders is mainly concentrated in its largest cities, Antwerp (4000) and Ghent (5500). Local governments call the presence of these Roma problematic, and publically state that they weigh disproportionately heavily on schools and local social services.

\section{Education and Roma communities}

Education is one of the core areas where significant problems with Roma populations have been reported. The most frequently cited problems are low levels of attendance and poor educational attainment (Hemelsoet 2013; Scullion and Brown 2013). Civic society organizations and schools in Flanders confirm these problems are more intense among Roma pupils when compared to non-Roma pupils in a comparable socioeconomic situation. (Savels and Hemmerijckx 2012; Geurts 2010).

Based on a literature review, we identified four perspectives negatively influencing Roma pupils' school careers (authors, in press). Although we present them separately below, we acknowledge that in reality, they can overlap.

Firstly, scholars point to the negative influence of the socio-economic position of Roma families. A multi-problem situation consisting of high unemployment rates, poverty, bad housing and the absence of a 'learning climate' at home, is presented as the root of problematic educational participation (VMC 2010), pleading not to isolate the problems in the domain of education from other societal challenges Roma families face.

Secondly, scholars point to the negative impact of a history of racism and discrimination in the countries of origin (Hemelsoet 2013; Akhim et al. 2013). Because of experiences of discrimination and social exclusion, Roma people are reported to have developed a deeply rooted distrust towards the official institutes, such as 'schools' and other public bodies linked to the non-Roma society. The difficulties in attracting Roma youngsters towards schools are attributed to this 'internalized distrust'.

Thirdly, scholars found a cultural dissonance between mainstream education and traditional Romani educational strategies (Levinson and Sparkes 2005). Smith (1997, 244) locates this conflict 'in the opposing structures, values and interests which are used to support and maintain social cohesion in two very different societies.'

A fourth perspective sees the encountered difficulties as indicators of shortcomings of the educational system in its current form (e.g. Hemelsoet 2013; Bhopal and Myers 2009; Bhopal 2004). As such, the power of the education system as a 
tool for integration is being questioned. Hence, the solution lies not only with the fitting in of newcomer groups in the existing educational practices; but also in the questioning of these practices, and their modification to meet the needs and practices of these groups.

Above all, building trust with Roma families has proven to be vital to secure school access and achievement (Scullion and Brown 2013; Myers, McGhee and Bhopal 2010; Myers and Bhopal 2009).

\section{Education in a broader societal context}

Scholars have long maintained that the educational system is to a large extent a reflection of broader society (Bourdieu 1990; Hannerz 1992) and, as such, this crucial social institution cannot compensate for inequalities and stratification processes occurring in broader society (Bernstein 1971). When aspiring to tackle the educational situation of the Roma, schools therefore try to construct new paradigms and strategies to deal with this social inequality. In such contexts, for example, the idea of 'full service extended schools' has been developed (Cummings, Dyson and Todd 2011).

When analysing educational outcomes, different elements can have an important influence on school success: the general school climate, teachers' expectations about their pupils, the managing skills of principals, pupil's school engagement etc. (Rumberger and Lim 2008; Wang and Eccles 2012). The underlying rational when optimising and implementing specific strategies or projects, is that these elements can be altered (Downes 2013, 2014). Each actor within the school participates into the emerging processes from their specific position and role (Baysu, Phalet and Brown 2011; Fredricks, Blumenfeld and Paris 2004). However, these individual actors do differ on various psycho-social and socio-demographic dimensions; necessitating a variety of strategies to keep all involved and to optimize interaction. It is assumed that the more fluently these interactions between all actors involved occur, the stronger a student's engagement with and achievement in education processes will be. Research thus stresses the importance of a holistic design, involving all actors in the developed strategies or projects to counter social and educational inequalities (Downes 2013, 2014). These strategies range from the systemic-structural level, over the meso level of the schools and classrooms, to the micro-level of inter-individual interactions and intraindividual dispositions (Gibson et al. 2013). 
However, a major pitfall concerns the idea of 'education compensating for society'. What can schools actually do within their scope, the broader policy framework and the time and means at their disposal? Cummings, Dyson and Todd (2011) argue that schools often try to compensate for 'proximal' factors, as these are the ones they are confronted with in everyday life and are thus the most tangible. Yet, it is the more deeprooted and distal factors and processes that are expected to be most important for halting classic reproduction processes related to social class, minority status and related power differences. The question remains if and how a school can address these distal factors.

When designing interventions targeting in particular socially vulnerable pupils and their families, research has shown that developing clear one-on-one relationships between school and pupil/family are essential (De Witte and Cabus 2013). This relationship is a key factor in optimizing the broader school engagement of a pupil (and its parents). At the same time the school itself can opt for a more 'open door' policy aiming to incorporate community initiatives into the school environment. Schools that open their doors for extra-curricular activities can increase pupils' and parental engagement as the school itself creates an open image rather than a structurally closed one (Mahony and Cairns 1997; Marvul 2012).

Several practical applications described in the academic literature have the potential to foster positive relationships between parents and school staff: literacy classes for parents, an 'open-door' policy (Myers and Bhopal 2009), and the participation of the family in decision-making processes and learning activities (Flecha and Soler 2013). Nevertheless, 'a commitment on the part of the school to inclusion does not necessarily mean that inclusive values will be realized in practice or indeed shape practice' (Bhopal 2011, 479). It has, for example, been shown that even in schools known for their 'good practices', stereotypical images of Roma can still persist among teachers and many of them continue to judge Roma parents' concerns against their own norms. Such stereotypes prove to be difficult to change, although teachers' attitudes may improve when they have direct contact with the Roma population (Trentin et al. 2006).

As expected, such educational approach demands much from the involved educational actors and stakeholders and goes beyond traditional ideas about schooling. A critical point is to find a balance between the educational function of the school and its more social function, as school staff can feel burdened by the 'extra work' expected 
of them in full service schools (Dyson, Millward and Todd 2002). One relevant approach is to construct a school as a hub for a broader range of social services (next to educating of pupils), resembling the idea of 'inclusive education systems' which argues that 'schools' should be open to incorporating the life experiences and social context of all pupils (Banks and Banks 2010). This leads to the construction of community (oriented) schools or 'broad schools', the term commonly used in Flanders.

Roma families' trust in the educational system appears to be augmented when they know and trust one or more members of the school staff (e.g. Bhopal 2004; 2011; Myers and Bhopal 2009). Active consultation and involvement of parents and children in the educational process shows to be beneficial for improving the educational achievement of these pupils, as well as for reducing drop-out rates (Bhopal 2004). Moreover, trust seems to be increased when the schools and school staff deals effectively with reported racism and bullying incidents (Bhopal 2011; Derrington 2007, 2005). The importance of commitment and dialogue of the school staff with members of the Roma community hence comes to the foreground (Bhopal and Myers 2009; Flecha and Soler 2013).

Apart from Roma families and the school staff, intermediaries from social services are sometimes reported to make an extra connection between the school and Roma families. Such services often show to be positively valued by parents and children (Lloyd and McCluskey 2008); positive relationships with intermediaries seem to be beneficial for the relationship between families and the school (Bhopal 2004; O'Hanlon 2010). Nevertheless, the involvement of intermediaries also poses a threat to the direct communication between parents and the school (e.g. Bhopal and Myers 2009).

The presented review on Roma in educational settings reveals that the problems Roma pupils might face in education have a multi-faceted origin. An integrative approach involving families, children, teachers, community members and policy-makers through an egalitarian dialogue improves the educational achievement of Roma pupils (Scullion and Brown 2013; Flecha and Soler 2013). 


\section{Methodology}

\section{A theory-based stakeholder evaluation}

The research strategy is that of a theory-based stakeholder evaluation following a case study design (Hansen and Vedung 2010). The theory-driven approach to evaluation was developed as a reaction to the domination of input-output thinking in traditional evaluations, changing the evaluation's focus from 'what works?' into 'what is it about the intervention that makes it work, for whom and under what circumstances?' (Pawson and Tilley 1997; Weiss 1997). Theory-driven evaluators hold that for every intervention, a set of theoretical assumptions (program theories) exist about how the intervention will work out in reality, against which the illumination of cause and effect can be structured (Chen 2005). It is the evaluator's task to make explicit these theoretical assumptions and to put them to the test by focusing on contextual and intervening factors that contribute to the success or failure of the intervention.

\section{Description of the case}

A case study approach fits nicely with the theory-driven approach to evaluation, as it allows a comprehensive exploration of the operation of complex interventions, both as a whole, and in their natural contexts (Yin 2009). Because of the uniqueness of the case under evaluation, it was decided to adopt a single case study design, which leaves more room to focus in detail on the social processes and power relationships when unravelling the complexity of the context (Descombe 2003; Swanborn 2010). Theoretical generalization techniques are adopted to overcome the main weakness of a single case study: generating useful knowledge by studying the details of one specific case (Kennedy 1979).

The case of a primary school in Ghent (PSG) that successfully works with Roma pupils and parents, provides us with an interesting opportunity to study how its organisational model contributes to this success. Insight into the organisational mechanisms backing the school's success allows theoretical extrapolation to other (educational) contexts struggling with Roma integration.

PSG describes itself as a concentration school. This does not only point to the concentration of Roma pupils, but also to the concentration of families with low scores on social- and economic indicators. Sixty out of the 180 pupils (14 Slovakians, 46 Bulgarians) are registered as 'member of the traveling population'. PSG receives $150 \%$ 
of the standard government financial contribution per pupil for every pupil of this group. Furthermore, only 3 out of 180 pupils speak Dutch as the main language in the home environment and have a mother holding a degree of at least higher secondary education.

In spite of these realities, PSG succeeded in reducing truancy rates, building trust with the Roma parents and guaranteeing parent involvement. The school principle estimated a 90\%-participation rate of Roma parents in teacher-parent meetings. During our fieldwork, we also found an active presence of Roma parents in events hosted by the school, e.g. a first communion celebration, or a classroom dedicated to consultations between parents and a staff member for any issue the parents face, school-related or not. During the interviews, Roma parents spoke highly about the school staff and their child's wellbeing, and reported trust in positive educational outcomes.

\section{Data collection}

The data collection proceeded in three steps. Firstly, the researchers studied the school's website and a corpus of internal documents in order to get a first insight into the implicit and explicit theories guiding the PSG's daily practices, as well as into the design and implementation of activities.

Secondly, the researchers developed a questionnaire presenting this initial reconstruction of the school vision for discussion among a selection of stakeholders, including the school principal, the care coordinator, the Equal Education Opportunities ${ }^{1}$ (EEO)-coordinator, the bridging figure (mediator) and a sample of teachers. A total of eleven members of the school staff participated in the questionnaire and the follow-up focus group discussion. In this way, our initial interpretation of the school vision as distilled from the internal documents and the questionnaire was checked with the perspectives of the different stakeholders involved. Participants were asked to reflect on the feasibility of this theoretical model, and to illustrate their arguments with examples from their daily practice and experiences.

\footnotetext{
${ }^{1}$ The EEO-program aims to guarantee equal opportunities for all pupils: foreign-speakers, underprivileged, with learning disabilities, etc. Schools with specific pupil-profiles get funding to employ EEO-teachers and a EEO coordinator.
} 
In a third step, the completed questionnaires were analysed by the researchers. Two topics were selected and further discussed during a focus group discussion with the same respondents: (1) the attitude of the school team vis-à-vis societal change in general and the presence of pupils with a lower SES-background, Roma pupils in particular; and the implications of that change for the school team and school structure; and (2) the consequences of the implementation of the school model for the relations between and the functioning of the different team members.

\section{Findings}

In this section, we deconstruct and reconstruct the assumptions and guiding principles steering the school vision and strategy, using the documents found on the intranet. Secondly, we focus on the organizational structure of the school. Finally, we present the results of a questionnaire and follow-up focus group discussion with a sample of staff members, wherein these respondents reflect on the school dynamics and their place and functioning within the school structure.

\section{The Program Theory}

Based on the internal documents on PSG's intranet, we were able to reconstruct the program theory (PT) of PSG. This PT can be summarized as follows: 'It is the responsibility of the school team to offer a child optimal learning opportunities by maximizing the general well-being and the involvement of pupils; within school walls, but also outside school walls (at home, in the neighbourhood...).'

To implement this vision optimally, the school team thus needs to be active in following three 'learning domains': (1) internal student-school relations within the school environment, (2) relationships between the school and the parents/home environment and (3) the neighbourhood. Table 1. presents the deconstructed institutional vision into the three sub-sets of assumptions.

\section{INSERT TABLE 1}

\section{Implementing the vision: the school organization and team member profiles}

We found out how the theoretical assumptions whereon the school's vision is based, imply that the school team should no longer merely be concerned with the educational aspect of schooling. The wellbeing of their pupils also has to become a focus point. 
This causes an expansion of the target audiences of the school team. The pupils still are their core business. But in order to maximize equal learning opportunities, the school aspires to have an impact on the home environments as well, making the pupils' families a target group of the school team. To successfully meet certain needs of pupils and/or of their parents, the school team invests in the expansion of the social network, seeking cooperation with neighbourhood organizations and services. These thus become the third target group of the school team.

This seems challenging to the school, probably requiring new skills and expertise surpassing the pedagogical aspect of education to successfully build out the aspired PT. This also implies another addition to the workload of the school team. Hence, how PSG is internally distributing the workload and what are the different team members' profiles in order to successfully implement the PT into the daily school practice?

\section{The different team members' profiles}

The different profiles within the school team can be linked to the two core businesses of PSG: education and well-being/care.

The largest group consists of the regular intra-muros teachers. Their main concern is to make progress with the pupils in the course of the academic year. One EEO-coordinator provides the teachers with the tools and/or supplementary support to keep underprivileged pupils on board. However, the school vision asks of every individual class teacher to act as a so-called EEO-teacher, paying attention to the needs of every single pupil.

To cover the 'well-being/care' side at PSG, a care-coordinator is employed. She/he is responsible for those pupils whose school success and attainment is acutely threatened by elements that are external to the school (home environment or neighbourhood context); but who manifest within the school walls. She/he assesses the situation and tries to work out a solution. This sometimes requires the consultation of other organizations or services involved with the particular case.

The link between the team members focusing on 'education' on the one side, and those working on 'well-being' on the other, is a mediator called the 'bridging figure'. Today, they are the representative of the school in the pupil's home environments and the go to-point for parents, teachers and neighbourhood organizations. It is the bridging figure's task to pick-up the signals given by teachers or 
parents about a pupil's school attainment or general well-being, and to frame those signals within the specific pupil's home context, striving for a shared solution to overcome the difficulties faced. Doing so, they provide vital input to the care coordinator, who in turn is responsible to work out a solution strategy. The work terrain of the bridging figure therefore lies for the most part outside the school walls.

\section{Organizing interaction: different meeting arenas in and around PSG}

The school vision is developed and consequently implemented throughout contact moments between the different stakeholders. These processes are facilitated by the organizational structure of PSG, providing both formal and informal contact moments within the school team, but also between the school team members and other stakeholders (parents, neighbourhood organizations etc.). We find how the relationship with the parents is mainly constructed using informal contact moments in a mostly familiar and unthreatening or 'safe' context. These moments are set up based upon specific aims and assumptions about the relationship between team members and parents.

\section{INSERT TABLE 2}

The documents on the PSG intranet reveal the existence of a biannual school team meeting. The meetings are used to (re)align the different viewpoints of the school team members, and are chaired by the school principal but prepared together with the EEO- and care coordinators and the bridging figures. At the beginning of the academic year, this meeting serves as a platform to communicate about the school vision and the priorities for the starting working year. At the end of the academic year, it has a more evaluative purpose and is used to improve the existing strategies or approve new interventions. Every team member is asked to complete an evaluation form in preparation for the meeting, which guarantees their participation in the school policy development. The results of these evaluations are presented at the team meeting and used to define the priorities for the coming working year collectively. This approach stimulates the necessary broad support for the general school vision and the subsequent actions. Additionally, the school principal adopts a more informal open door-policy, allowing every member of the school team to come to him to informally discuss new ideas, general concerns or specific problems. 
Although the school council exists as a formal discussion arena between school staff and parents, it is the specific school strategy to keep the contact opportunities between parents and team members as accessible and informal as possible. During our interview with the school principal, it became clear that the underlying assumption is that most parents are unfamiliar with this kind of formal consultative bodies, or will not easily participate in them because of language problems, initial distrust or other thresholds. To reach the parents anyhow, getting to know their concerns and to gradually build a relationship of trust with them, several informal contact moments are actively pursued.

For example, the school principal, the EEO- and care coordinators, and the bridging figures regularly are to be found at the school gate at the beginning and end of a school day. There they are able to informally discuss the situation in school or at home. They want to be visible to the parents and approachable whenever these parents feel a need to talk.

During our fieldwork in PSG, we also visited a classroom next to the playground, that is reused as a dedicated 'parent room'. Two mornings a week, parents can come here after dropping off their children and have a coffee and a chat with the bridging figure or the care coordinator. Parents frequently use this opportunity to ask help with matters that are unrelated to school, e.g. the interpretation of utility bills they themselves do not understand; or to ask help drafting a letter to official government agencies. Although this asks a fair amount of time from the bridging figure or care coordinator, the effort is made in order to gain the trust of the parents.

A few days before the official start of the academic year, the school also organizes 'open school days', allowing the pupils and their families to take a tour of the school and to get to know the school team. This initiative is taken in order to make the first contact between the school team and the families a positive one. For the same reason, preventive home visits to certain families are undertaken by the bridging figures and/or care coordinator, allowing them to assess the home context of the pupil without immediately having to intervene in it after a problem surfaces. Simultaneously, by presenting themselves to the parents, the bridging figure and/or care coordinator aspire to become an accessible go-to point for the parents in case of questions or problems.

The documents on the school's intranet reveal how the relationship between the school and the neighbourhood is covered by the 'school mediator team' and by 
different ad-hoc working groups. The latter organize specific projects, e.g. art or music projects, with local organizations or people. These working groups consist of teachers who volunteer for a specific project, and the bridging figure. The mediator team focusses on the more general approach and strategies to achieve a long-lasting relationship between school, family and neighbourhood. It aims to share and bundle the experiences of the different projects and to consolidate cooperation with ad-hoc partners by maintaining the overview of the different partners and projects.

As we remember from the PT above, the reason to work within school, with parents and with neighbourhood organizations, was to guarantee the school success and learning opportunities of pupils by helping to provide for a stable environment. Two formal discussion arenas are set up to guide this process. The care team is a meeting of the care coordinator, the bridging figure, the teacher and external partners. On a weekly basis, the individual cases of pupils with problems within and/or outside the school walls are being discussed with the relevant partners, including as much as possible the partners from outside the school. The care coordinator chairs these meetings, and is responsible to map the different problems a specific pupil faces as well as the different partners that are working on the case. Based on this information, a general strategy is designed to get the pupil at risk back on track.

Doing so, the broader extra-muros context wherein the pupil finds himself/herself is always taken into account; and the different stakeholders are kept in the loop and actively contribute to the development of the intervention.

The Pedagogical Core Team (PCT) brings together the school principal, the EEOand care coordinator and the bridging figure. Whereas the care team meeting discussed individual cases, the aim of the PCT is to discuss the developments in the school operation on a more general level, taking into account the information collected in the formal discussion arenas and during the informal contact moments. The PCT focusses on the patterns that become visible, and discusses the school's responses to them. The PCT can therefore be seen as a central hub, receiving, processing and channeling the available information. Their conclusions and recommendations are presented and discussed with the entire school team at the biannual general team meetings.

\section{The school model through the eyes of the different school members}

We now take into account the experiences of the school team members who function within the organizational model presented above. 
Societal change and the influence on the school team and school structure

In the questionnaire, we asked the respondents to react to the following statement:

"Society, of which the school is part, has changed drastically during the last ten years, for example by the influx of migrants from Bulgaria/Slovakia." We learned how the members of the school team agreed on the changed reality and, as a consequence of that change, the new challenges for the school. However, the change was approached as an inherent, thus normal, characteristic of society. Throughout the discourses, the changed reality in itself never was presented as a problem, but rather as a challenge for the school to rethink itself. According to the team members, a flexible and dynamic mindset and the room to experiment seem to be the keys to cope with the reality.

"I do not believe there is a problem, but this asks for a different approach and a large amount of flexibility. I am convinced that this flexibility is present here, but it sometimes drains a lot of energy, because one never knows beforehand how it will be; you only know the moment you start working with the children. Only then can we see what is asked of us, as a person and as a team. The illiteracy, the low educational experience of these new pupils... demands a different approach.(...) This causes tension that asks for solutions. This again demands more energy and, above all, flexibility."

- F., teacher

This flexibility also is reflected in the organizational structure of the school.

"The team members are very flexible and available. Change is not seen as a problem here. The mentality of the school team is really different from an average Flemish school. This is something that really influences the way things can be done in PSG. The way in which the school is structured has a lot to do with this."

- G., principal

"It is evident that our school constantly seeks new approaches, assignments and responsibilities or regulations... (...) I assume that changes in the school structures can only come about when people start looking for solutions. Many of these solutions may afterwards turn out to be inadequate, but the only way to come to that conclusion is by trying. If one does not try and dare to change things, nothing will be achieved. I believe in continuous change and lifelong learning."

- J., teacher 
Another way in which the school vision is realized is by recruiting specific expertise that surpasses the pedagogical responsibilities of PSG. When appointing a new bridging figure in 2010, the school tried to go along with the societal changes by hiring a social worker. Doing so, the school took someone on board with the necessary expertise to work with underprivileged families and with the specific knowledge on social organizations and services to cooperate with. This illustrates how 'education' should no longer be seen as a job solely of licensed teachers, and how keeping a broader view can be useful.

"R: The choice to employ a social worker was a deliberate one. (...) We also discussed hiring someone from within the group; or someone who was fluent in a specific language.

I: So what made you hire a social worker in the end?

$R$ : It was partly because we wanted to provide more professional care. A social worker introduces specific knowhow you don't have as a teacher. Social maps, for example. In the end, it was the right decision. We made progress and now work more professionally than before."

- B., principal

The school team recognizes the importance of the bridging figure in the school operation and in the implementation of the school vision. The reactions of the teachers prove that the presence of a bridging figure has a real added value to the school practice.

\footnotetext{
"When I feel it is all too much and it weighs upon me, I involve the care team or the bridging figures."

- J., teacher

"Parents sometimes lean more easily towards the bridging figures; since they made the effort to build up trust. They have the time and space for it..."

- E., teacher
}

The different quotes all illustrate specific elements contributing to the success of the school operation. We found how a flexible and dynamic mindset of the school staff is also reflected in the organizational model of the school, whereby the presence of a bridging figure is clearly perceived as added value. However, we also found a tension between both pillars of the school operations: between caring and educating. In what follows, we elaborate on this. 
A tension between two sides of the model: caring or educating?

In spite of the school team's rather positive or constructive approach to the recent influx of pupils from Eastern Europe, and the different interventions that were made to steer the school in the right direction, we still noticed a field of tension within the school model and between the team members. These tensions become visible throughout the quotes as frictions between the part of the school team that is directly responsible for the education on the one side, and the team members responsible for the well-being and care-component on the other.

\footnotetext{
“Education and wellbeing are intertwined. There is a difference however, in the approaches. Teachers expect a swift solution and visible result on the short term. But this is not how it goes in social work. It takes time to work on empowerment, sometimes a lot of time. The result sometimes only becomes visible after months or even years. As a bridging figure, I am often confronted with specific frustrations teachers have. The situation is not evolving fast enough from their point of view. There are (sometimes unspoken, but perceptible) expectations of the bridging figure that I cannot meet." - D., bridging figure
}

\begin{abstract}
"But the focus is different and sometimes hard to reconcile. The focus lies with the society on the one hand and with the education on the other. (...) They cannot be seen separately, but sometimes are. It does not necessarily have to be a problem, but it is never easy.(...) Sometimes however, I do have the feeling that these extra profiles [bridging figures, care coordinator, authors] float off further and further from what we experience in the classrooms. People in those functions have a different 'feel' for what happens within the school walls when compared to the teachers, who are really 'in it'. Because of this, it sometimes is not easy to be understood in certain situations, since those people approach the situation from a different perspective"

-J., teacher
\end{abstract}

The distance between the two elements of the school operation is also noticed by the care coordinator, who reflects on the role and use of the care team: the presence and availability of team members working on the well-being of the pupils does not imply that cooperation between all members of the school team is no longer necessary. Problematic cases cannot be pushed off onto someone else. 
solution together with them. On the other hand, I find they sometimes formulate a cry

for help too easily, without actively taking initiative to address certain situations."

- A., care coordinator

We thus indicate a potential pitfall in the organizational model of PSG: the tension between the staff members involved with 'caring' activities and those working on the educational aspects of the school operation can become too large. This schism in turn threatens the feeling of a shared responsibility for the totality of the school project.

\section{Discussion and conclusion}

In this paper, we aimed to gain insight into the mechanisms steering the practice of a primary school in Ghent (PSG) with a majority of Roma pupils. As PSG is seen as a 'good practice' by civil society organizations and local policy makers, we analyzed how the organizational model contributes to the favourable outcomes (and possible pitfalls) and to the establishment of trust between the school staff and Roma parents. Our hypothesis was that the success of the school strategy lies in a congruence between the underlying principles guiding the school's daily practice on the one hand and the needs and traits of the target audience on the other. Furthermore, we hypothesized that the success of the strategy also lies in its implementation and in the support from the school staff.

Our reconstruction and analysis of the guiding principles behind the organizational model of the primary school in Ghent (PSG) and the implementation thereof, identified two general reasons making this approach a good practice for working with Roma parents, confirming our hypotheses.

Firstly, we found a congruence between the program theory in PSG and the needs and profile of their target audience. Overcoming the distrust of Roma parents for non-Roma institutions like the school is vital to secure school access and achievement of Roma pupils. Doing so, the commitment and dialogue of the school staff with members of the Roma communities proves to be important. Additionally, intermediaries from social services can form an extra connection between the school and Roma families. When we compare these formulated Roma-specific recommendations with the more generic 'broad' school model that lies at the basis of PSG's working strategy, the complementarity between both approaches becomes apparent. 
Secondly, we point out some of the elements and choices that were made when putting the program theory into practice, and that contribute to the sustainability of the model. The following three groups of influential elements are thus all linked to the implementation of the underlying principles and theories:

(1) The general school vision and policies are broadly supported by the school staff, who has to implement the interventions developed from those principles. Although some tension was still reported between the team members working on the care aspect and those working in the classrooms; there clearly is a general appreciation for the school policy among the team members.

The organizational model of the school further strengthens this support, since it is characterized by an 'open door' policy, and a horizontal configuration of different meetings in informal and formal arenas. As such, the school model represents the vision of the school as a shared project that thrives on an equally shared responsibility for the process and the outcomes. During our fieldwork, it also became clear how open-minded and flexible the respondents are able to be when dealing with the changing socioeconomic realities they face. However, it is not clear whether this 'mindset' was developed when working within the school system; if it already was present before being a part of the school team; or if both elements positively influenced each other.

(2) The school strategy is sustainable because some important human and logistical resources are available. Most noteworthy is the presence of the dedicated carecoordinator and bridging figures who have taken on tasks that traditionally lie outside of the school operations. However, we do have to point out that the EOO-funding for bridging figures is still project-based, threatening the development and exchange of expertise by bridging figures in unfavourable contracts.

The school also invests in logistical support to reach Roma parents. There is, for example, the availability of a room with a coffeemaker especially dedicated to parents, or the use of the catholic chapel adjacent to the school for first communion celebrations.

(3) The decision of the school management to attract specific expertise to the school is also an important element helping to guarantee an optimal functioning of the program theory in practice. Given the fact that the complexity of some situations surpasses the pedagogical aspect of education, the school hired someone with the necessary expertise to work with underprivileged families and with the specific knowledge on social organizations and services to cooperate with. In conclusion, our analysis illustrates the complex interplay of different elements 'making or breaking' the 
school policy on vulnerable (Roma)pupils and their parents. The results of the PSG model not only show an interesting congruence between the designers of the interventions and its implementers, but also between the guiding principles and underlying theories on the one hand and specific profiles and needs of the target audiences on the other. The positive influences from this congruence are further strengthened by a participative policy-making process and a shared responsibility for the outcomes of school policies. Furthermore, the designed interventions are backed with the necessary human and logistical capital and expertise.

Nevertheless, some tensions still remain. Throughout the discourses of the school staff, a distance between the 'caring'-aspect and the 'educating'-aspect of the school operations became visible. In spite of the broad support for the general school strategy aiming to augment pupils' chances of a successful school career by also working outside the school walls, there seem to be different expectations regarding the term wherein results are expected and efforts start to pay off. Further synchronization and communication about the priorities of both groups seems necessary.

\section{References}

ABB (Agentschap Binnenlands Bestuur) 2012. Vlaams Actieplan MOE(Roma)Migranten. Brussel: Vlaamse Overheid.

Banks, J. and Banks, C. 2010. Multicultural Education: Issues and perspectives. 7th edition. USA: John Wiley and Sons.

Baysu, G., Phalet, K. and Brown, R. 2011. Dual identity as a two-edged sword: identity threat and minority school performance. Social Psychology Quarterly 74(2): 121143.

Bernstein, Basil. 1971. Class, Codes, and Control: Theoretical Studies Towards a Sociology of Language. London: Routledge and Kegan Paul.

Bhopal, K. and Myers, M. 2009. Gypsy, Roma and Traveller Pupils In Schools In The Uk : Inclusion And 'Good Practice'. International Journal Of Inclusive Education 13: 299-314.

Bhopal, K. 2004. Gypsy Travellers and Education: Changing Needs and Changing Perceptions. British Journal of Educational Studies 52: 47-64.

Bhopal, K. 2011. 'This is a school, it's not a site: teachers' attitudes towards Gypsy and Traveller pupils in schools in England, UK. British Educational Research Journal 37: 465-483. 
Bourdieu, P. 1990. The Logic of Practice. California: Stanford University Press.

CFHR (Committee for Human Rights) 2012. Human rights of Roma and Travellers in Europe. Strasbourg Cedex: Council of Europe Publishing.

Chen, H.-T. 2005. Practical Program Evaluation. Thousand Oaks: SAGE Publications.

Cummings, C., Dyson, A. and Todd, L. 2011. Beyond the School Gates. Can full service and extended schools overcome disadvantage? London: Routledge.

Derrington, C. 2005. Perceptions of behavior and patterns of exclusion: Gypsy Travellers students in English secondary schools. Journal of Research in Special Educational Needs 52: 55-61.

Derrington, C. 2007. Fight, flight and playing white: An examination of coping strategies by Gypsy Traveller Adolescents in English secondary schools. International Journal of Educational Research 46: 357-367.

De Witte, K. and Cabus, S. J. 2013. Dropout prevention measures in the Netherlands, an explorative evaluation. Educational Review 65(2).

Downes, P. 2013. Developing a framework and agenda for students' voices in the school system across Europe: From diametric to concentric relational spaces for early school leaving prevention. European Journal of Education 48(2).

Downes, P. 2014. 'Prevention of early school leaving through teacher education: Some European perspectives.' in Rabinsteiner P.-M. and Rabinsteiner G. (eds.) Internationalization in Teacher Education. pp. 17-31. Hohengeher: Schnieder Verlag.

Dyson, A., Millward, A. and Todd, L. 2002. A study of the extended schools demonstration projects. Research report 381. Londen DfES.

European Commission. 2011. An EU Framework for National Roma Integration Strategies up to 2020. COM(2011) 173 final. Brussels.

European Commission. 2011. Working together for Roma inclusion. The EU Framework explained. Luxembourg: Publications Office of the European Union.

Flecha, R. and Soler, M. 2013. Turning difficulties into possibilities: engaging Roma families and students in school through dialectic learning. Cambridge Journal of Education 43: 451-465.

FRA (Fundamental Rights Agency) 2012. The situation of Roma in 11 EU Member States. Survey results at a glance. Luxembourg: Publications Office of the European Union. 
Fredricks, J. A., Blumenfeld, P. C. and Paris, A. H. 2004. School engagement: Potential of the concept, state of the evidence. Review of Educational Research 74(1): 59-109.

Geurts, K. 2010. Met één achterste kan je niet op twee paarden zitten. Romaleerlingen op de schoolbanken. Handboek leerlingenbegeleiding. Antwerpen: Plantyn.

Gibson, M. et al. 2013. 'Different systems, similar results: youth of immigrant origin at school in California and Catalonia.' in Alba. R. and Holdaway, J. (eds.) The children of immigrants at school: a comparative look at integration in the United States and Western Europe. pp. 84-119. New York: New York University Press.

Hannerz, U. 1992. Cultural Complexity: Studies in the Social Organization of Meaning. New York: Columbia University Press.

Hansen, M. B. and Vedung E. 2010. Theory-Based Stakeholder Evaluation. American Journal of Evaluation 31: 295-313.

Hemelsoet, E. 2013. A critical appraisal of policies and practices focusing upon the right to education: The case of the Roma in Ghent. Doctoral thesis. Ghent: Ghent University.

Kennedy, M.M. 1979. Generalizing from single case studies. Evaluation Quarterly 3(4): 661-678.

Levinson, M. and Sparkes, A. 2005. Gypsy Children, Space, And The School Environment. International Journal Of Qualitative Studies In Education 18: 751772 .

Levinson, M. 2007. Literacy in English Gypsy Communities: Cultural Capital Manifested as Negative Assets. American Educational Research Journal 44: 5-39.

Lloyd, G. and McCluskey, G. 2008. Education and Gypsies/Travellers: 'contradictions and significant silences'. International Journal of Inclusive Education 12: 331-345.

Mahony, J. L. and Cairns, R. B. 1997. Do extracurricular activities protect against early school dropout? Developmental Psychology 33(2): 241-153.

Marvul, J. 2012. If You Build It, They Will Come: A Successful Truancy Intervention Program in a Small High School. Urban Education 47(1): 144-169.

Myers, M. and Bhopal, K. 2009. Gypsy, Roma and Traveller Children in Schools: Understandings of Community and Safety. British Journal of Educational Studies 57: 417-434.

Myers, M., McGhee, D. and Bhopal, K. 2010. At the crossroads: Gypsy and Traveller parents' perceptions of education, protection and social change. Race Ethnicity and Education 13: 533-548. 
O'Hanlon, C. 2010. 'Whose education? The inclusion of Gypsy/Travellers: continuing culture and tradition through the right to choose educational opportunities to support their social and economic mobility. Compare: A Journal of Comparative and International Education 40: 239-254.

Pawson, R., and Tilley, N. 1997. Realistic Evaluation. London: Sage.

Rumberger, R. and Lim, S.A. 2008. Why students drop out of school: A review of 25 years of research. Santa Barbara: University of California Santa Barbara.

Savels, H. and Hemmerijckx, B. 2012. Op weg naar een betere scholing van Roma in Gent. Gent: Intercultureel Netwerk Gent.

Scullion, L. and Brown, P. 2013. What's working?: Promoting the inclusion of Roma in and through education. Transnational policy review and research report. University of Salford: Salford Housing and Urban Studies Unit.

Smith, T. 1997 Recognising Difference: The Romani 'Gypsy’ Child Socialization And Education Process. British Journal Of Sociology Of Education 18: 243-256.

Swanborn, P. 2010. Case Study Research: What, Why and How? London: Sage.

Trentin, R., Monaci, M.G., De Lumé, F. and Zanon, O. 2006. Scholastic Integration of Gypsies in Italy: Teachers' Attitudes and Experience. School Psychology International 27: 79-103.

VMC (Vlaams Minderhedencentrum) 2010. Werknota: Roma in Vlaanderen. Knelpunten en aanbevelingen. s.l., Vlaams Minderhedencentrum.

Wang, M.-T. and Eccles, J.S. 2012. Social support matters: Longitudinal effects of social support on three dimensions of school engagement from middle to high school. Child Development 83: 877-895.

Weiss, C.H. 1997. Theory-based evaluation: Past, present, and future. New Directions for Evaluation 76: 41-55.

Yin, R.K. 2009. Case Study Research: Design and Methods, Thousand Oaks: Sage. 